\title{
Why Devote an Entire Issue to the Global Justice Index
}

\section{Sujian Guo ${ }^{1}$}

Published online: 9 June 2021

(c) Fudan University 2021

The reason why the editors of the Chinese Political Science Review have chosen to devote an entire issue of the journal to publishing the "Global Justice Index Report 2020 " is not only because the global justice debate has been raging for several decades, but also more importantly, because the global justice index is a pioneering work in today's world that makes the first attempt to comprehensively measure the performance and contribution of nation states to greater justice at the global level, covering 52 countries around the world across 10 issue areas, and up to 127 countries if the issue areas of climate change and education, which suffer from missing values, are excluded. The index presents a rich, comprehensive picture of global justice that offers a guide to global justice for the international community, nation states, policy makers, and individuals who want to observe states' annual achievements and changes over time. The index has direct relevance to the practice of justice at the global level, and serves as a barometer for the international community to implement and monitor global justice across different issue areas, enabling international organizations and policymakers to target resources and design policies more effectively. The index can also be used as an analytical tool to compare relevant global justice issues across nations or as a dependent variable or independent variable in causal analysis.

The Global Justice Index is a multiyear research project of the Fudan-IAS, initiated and led by Sujian Guo, and has resulted in two major publications, a theoretical paper titled "Conceptualizing and Measuring Global Justice: Theories, Concepts, Principles and Indicators" published in Fudan Journal of the Humanities and Social Sciences (Vol. 12, No. 4, 2019), and the "Global Justice Index Report" in Chinese Political Science Review (Vol. 5, No. 3, 2020). The "Global Justice Index Report 2020 " is the second annual report in an annual series, and is based on the theories, concepts, criteria for assessment, measurements, methods, and indicators developed in the theoretical paper.

Sujian Guo

sguo@fudan.edu.cn

1 Fudan Institute for Advanced Study in Social Sciences, Fudan University, Shanghai, China 